\title{
PERBAIKAN INTERIOR PADA MAJELIS TAKLIM AL MUSA'ADAH, DESA KEBASIRAN, KECAMATAN PARUNG PANJANG, KABUPATEN BOGOR
}

\author{
Sintia Dewi Wulanningrum ${ }^{1}$ dan Yunita Ardianti Sabtalistia ${ }^{2}$ \\ ${ }^{1}$ Prodi S1 Arsitektur, Jurusan Arsitektur dan Perencanaan, Fakultas Teknik, Universitas Tarumanagara Jakarta \\ Email: sintiaw@ft.untar.ac.id \\ ${ }^{2}$ Prodi S1 Arsitektur, Jurusan Arsitektur dan Perencanaan, Fakultas Teknik, Universitas Tarumanagara Jakarta \\ Email: yunitas@ft.untar.ac.id
}

\begin{abstract}
Majelis Taklim Al Musa'adah is a place that used by the residents of Kebasiran Village, Parung Panjang to do religious activities, such as; recitation for women, study religion, place to studying of religion for children. However, the inadequate condition of the interior of the building and the lack of supporting facilities (desks for studying, blackboards, storage racks) have made security activities less comfortable. By looking at these condition of the Al Musaadah Taklim Council, Kebasiran Village, RT 04 RW 01, Parung Panjang, Bogor, are needed that require cooperation between various parties so that this can be realized. The output of the activity is an articles in the Bakti Masyarakat Indonesia Journal, and additional output is design The solution is planned through upgrading the interior of the building and supporting facilities, so that religious activities can be carried out optimally. Interior improvements which is the wall color improvement is implemented by applying colors that are often used in Islamic architectural concepts, green as an element of nature. As well as arrangement of furniture such as adding tables for religious activities, adding shelves for storage of religious books and adding blackboards to support religious activities. The role of the community is also needed to maintain cleanliness and maintain facilities and infrastructure. Several things for future improvements include lighting arrangement, additional fans and additional ornaments of the interior.
\end{abstract}

Keywords: improvement, interior, majelis taklim

\begin{abstract}
ABSTRAK
Majelis Taklim Al Musa'adah merupakan tempat yang digunakan warga Desa Kebasiran Parung Panjang untuk melakukan kegiatan keagamaan seperti pengajian khusus wanita, belajar ilmu agama, sebagai tempat mengaji bagi anak-anak di sekitar Majelis. Namun, kondisi interior bangunan yang kurang layak serta kurangnya fasilitas penunjang (meja untuk belajar, papan tulis, rak penyimpanan), menyebabkan aktivitas keagamaan menjadi kurang nyaman. Dengan melihat kondisi eksisting Majelis Taklim Al Musaadah, Desa Kebasiran, RT 04 RW 01, Kecamatan Parung Panjang, Kabupaten Bogor saat ini, maka dibutuhkan upaya yang menuntut kerja sama antar berbagai pihak agar hal itu dapat diwujudkan. Luaran kegiatan berupa artikel pada Jurnal Bakti Masyarakat Indonesia, serta luaran tambahan berupa karya desain. Solusi yang direncanakan yaitu melalui perbaikan interior bangunan serta fasilitas penunjang, sehingga kegiatan keagamaan dapat berjalan secara optimal. Perbaikan interior berupa perbaikan warna dinding, dengan menerapkan warna yang sering digunakan pada konsep arsitektur islam, yaitu warna hijau sebagai unsur alam. Serta penataan furnitur seperti penambahan meja untuk tempat kegiatan keagamaan, penambahan rak untuk tempat penyimpanan buku agama dan penambahan papan tulis untuk menunjang kegiatan keagamaan. Peran masyarakat juga diperlukan untuk menjaga kebersihan, merawat sarana dan prasarana. Beberapa hal yang masih perlu ditingkatkan antara lain penataan cahaya, penambahan kipas angin dan penambahan ornamen pada interior.
\end{abstract}

Kata kunci: perbaikan, interior, majelis taklim

\section{PENDAHULUAN}

Majelis Taklim Al Musa'adah merupakan tempat yang digunakan warga Desa Kebasiran Parung Panjang untuk melakukan kegiatan keagamaan seperti pengajian, belajar ilmu agama, sebagai tempat mengaji anak-anak sekitar serta sebagai tempat kegiatan keagamaan yang lainnya. Majelis Taklim Al Musa'adah khusus digunakan oleh para wanita dan anak-anak di sekitar perkampungan. Majelis Taklim Al Musaadah berada di kawasan perkampungan, tepatnya di Desa Kebasiran, RT 04 RW 01, Kecamatan Parung Panjang, Kabupaten Bogor yang berjarak 38,5 KM dari Universitas Tarumanagara. 


\section{Analisis Situasi}

Keberadaan majelis taklim dilindungi oleh undang-undang dan pemerintah RI. Pada Pasal 26 (1) pendidikan nonformal diselenggarakan bagi masyarakat yang memerlukan layanan pendidikan yang berfungsi sebagai pengganti, penambah dan atau pelengkap pendidikan formal dalam rangka mendukung pendidikan sepanjang hayat. (2) Pendidikan nonformal berfungsi mengembangkan potensi potensi peserta didik dengan penekanan pada pengetahuan dan keterampilan fungsional serta pengembangan sikap dan kepribadian professional (Depag, 2006).

Istilah majelis ta'lim berasal dari bahasa Arab yang terdiri dari dua suku kata yaitu majelis yang berarti tempat duduk dan ta'lim yang artinya belajar. Dengan demikian, secara bahasa yang dimaksud majelis ta'lim adalah tempat belajar. Majelis ta'lim adalah sebuah lembaga pendidikan nonformal yang memiliki jamaah dengan jumlah yang relatif banyak, usia yang heterogen, memiliki kurikulum berbasis keagamaan dan waktu yang fleksibel sesuai kebutuhan jamaah (Puslitbang, 2007). Majelis ta'lim menurut Muhsin (2017) adalah tempat atau lembaga pendidikan, pelatihan, dan kegiatan belajar mengajar dalam mempelajari, mendalami, dan memahami ilmu pengetahuan agama Islam dan sebagai wadah dalam melaksanakan berbagai kegiatan yang memberikan kemaslahatan kepada jamaah dan masyarakat sekitarnya. Menurut Helmawati (2013) Majelis ta'lim adalah tempat memberitahukan, menerangkan, dan menggambarkan suatu ilmu, baik ilmu agama maupun ilmu pengetahuan dan keterampilan yang dilakukan secara berulangulang untuk mencapai ridha Allah SWT, serta untuk menanamkan dan memperkokoh akhlak.

Majelis taklim dilihat dari jamaahnya, antara lain: Majelis taklim kaum ibu/muslimah/perempuan; Majelis taklim kaum bapak/muslimin/laki-laki; Majelis taklim kaum remaja; Majelis taklim anakanak; Majelis taklim campuran laki-laki dan perempuan/kaum bapak dan ibu. Sedangkan berdasarkan dari tempatnya, majelis taklim terdiri dari: Majelis taklim masjid atau mushola; Majelis taklim perkantoran; Majelis taklim perhotelan; Majelis taklim pabrik atau industri; Majelis taklim perumahan.

Menurut Binmas Islam (1995), fungsi Majelis ta'lim antara lain: sebagai lembaga pendidikan non formal Islam berupa pengajian; sebagai majelis pemakmuran rumah ibadah; sebagai majelis pembinaan aqidah, ibadah, dan akhlak; sebagai tempat peningkatan wawasan perjuangan Islam; sebagai organisasi untuk meningkatkan pengelolaan amaliah berupa zakat, infaq, dan shadaqah.

Berdasarkan kajian literatur Majelis Taklim Al Musaadah jika dilihat berdasarkan jamaahnya termasuk Majelis taklim kaum ibu/muslimah/perempuan dan Majelis Taklim untuk anak-anak. Sedangkan jika dilihat dari tempatnya, majelis taklim termasuk majelis yang berada di lingkungan perumahan atau permukiman penduduk.

\section{Permasalahan Mitra}

Pada eksisting Majelis Taklim terdapat beberapa permasalahan antara lain; penutup plafon yang mulai rusak, penutup bukaan yang minim, kurangnya prasarana pada majelis (kurangnya meja untuk kegiatan keagamaan, tidak adanya rak untuk penyimpanan, tidak adanya papan tulis untuk kegiatan belajar mengajar, jumlah karpet yang terbatas, penerangan dalam ruang yang minim serta penghawaan buatan yang berasal dari kipas angin sangat minim, yang mana hanya terdapat satu buah kipas di sisi barat, serta kurangnya buku-buku keagamaan maupun Al Qur'an untuk kegiatan belajar mengaji para ibu dan anak-anak). 


\section{Gambar 1}

Permasalahan pada Majelis Taklim Al Musa'adah
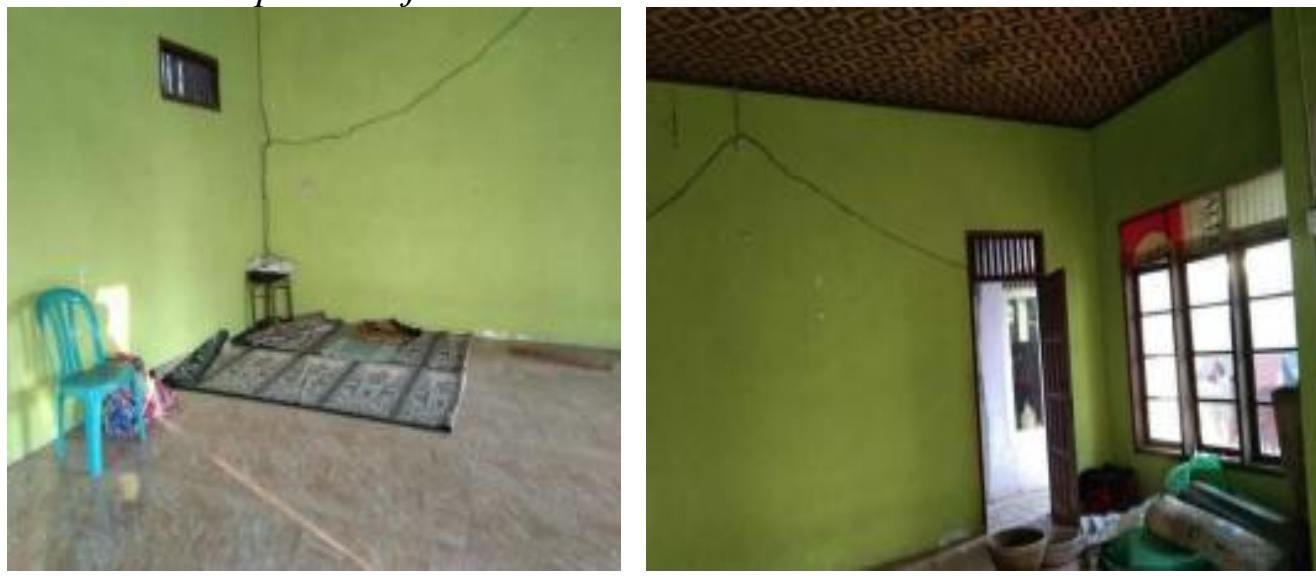

\section{METODE PELAKSANAAN PKM}

Perbaikan interior pada Majelis Taklim Al Musa'adah merupakan tahap lanjutan dari kegiatan PKM sebelumnya dengan judul "Penataan interior Majelis Taklim Al Musa'adah Desa Kebasiran, Kelurahan Parung Panjang", dengan luaran berupa desain interior. Pada PKM ini, kegiatan yang akan dilaksanakan adalah penataan Majelis Taklim Al Musa'adah. Sebelum proses perbaikan Majelis Taklim, penulis telah melakukan kegiatan antara lain: melakukan kajian literatur, tahap survey pada Majelis Taklim serta wawancara dengan Mitra yaitu Bapak Patudin selaku Ketua RW, serta tahap desain. Pada tahapan perbaikan berupa pengecatan interior, perbaikan sarana dan prasarana di Majelis Taklim Al Musa'adah.

\section{HASIL DAN PEMBAHASAN}

Tahap pra pelaksanaan yang diawali dengan diskusi bersama Mitra yaitu Bapak Patudin, selaku ketua RT 04, RW 01, Desa Kebasiran, Parung Panjang. Pada tahap ini direncanakan untuk pengecatan dinding bagian dalam dan bagian luar. Proses pengecatan berlangsung satu minggu. Pada proses pengecatan tim dibantu oleh satu orang tukang yang berasal dari warga sekitar Majelis Taklim.

\section{Gambar 2}

Interior Majelis Taklim Sebelum Tahap Pelaksanaan
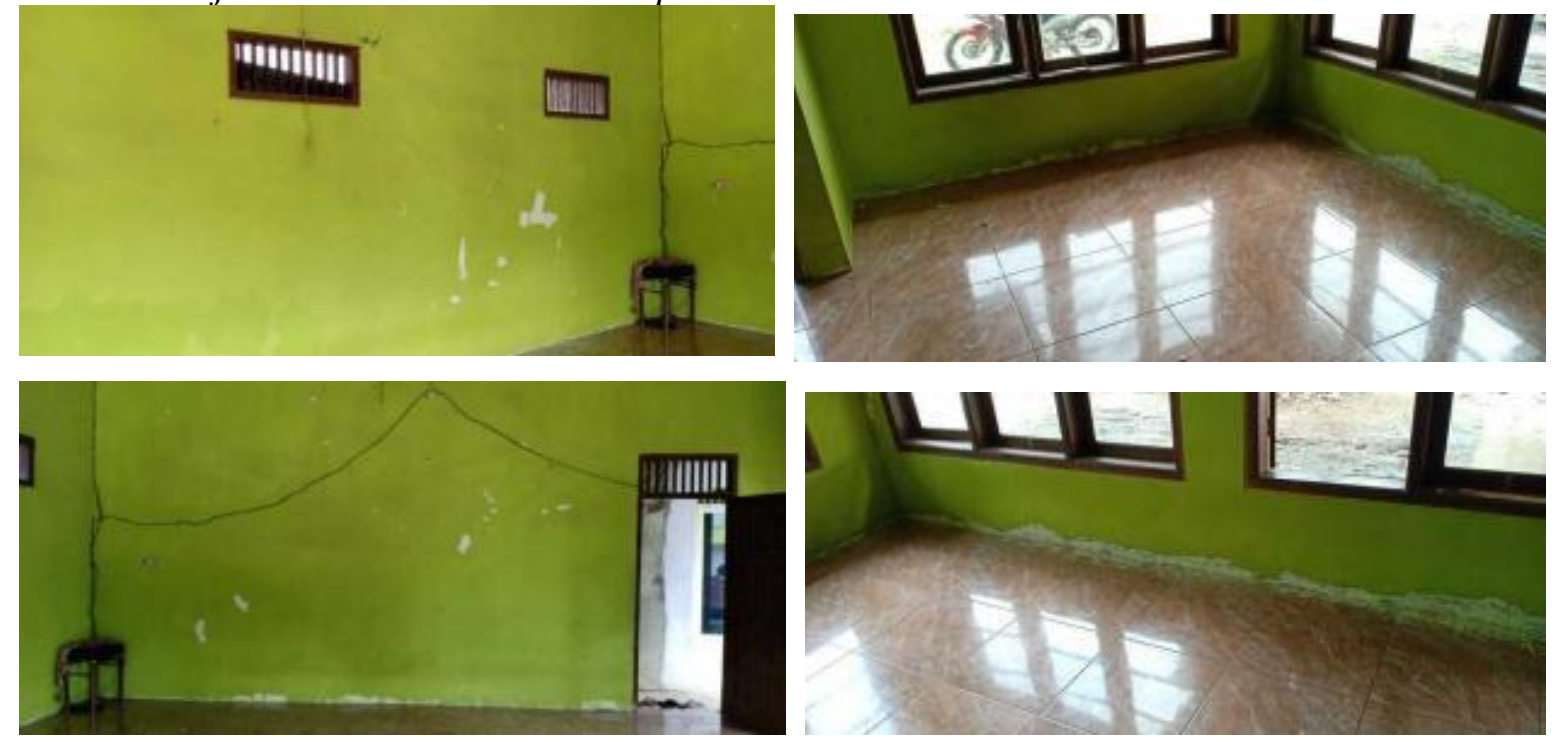
Kondisi interior pada Majelis Taklim Al Musa'adah sebelum dilakukan tahap penataan atau pelaksanaan, masih kurang tertata dan kurang perabot. Pada interior atau ruang dalam Majelis Taklim sudah mulai mengelupas, sedangkan perabot hanya ada satu kursi kayu dan karpet. Oleh sebab itu diperlukan penambahan furniture pada Majelis Taklim.

\section{Gambar 3}

Tahap Pelaksanaan Pengecatan Interior

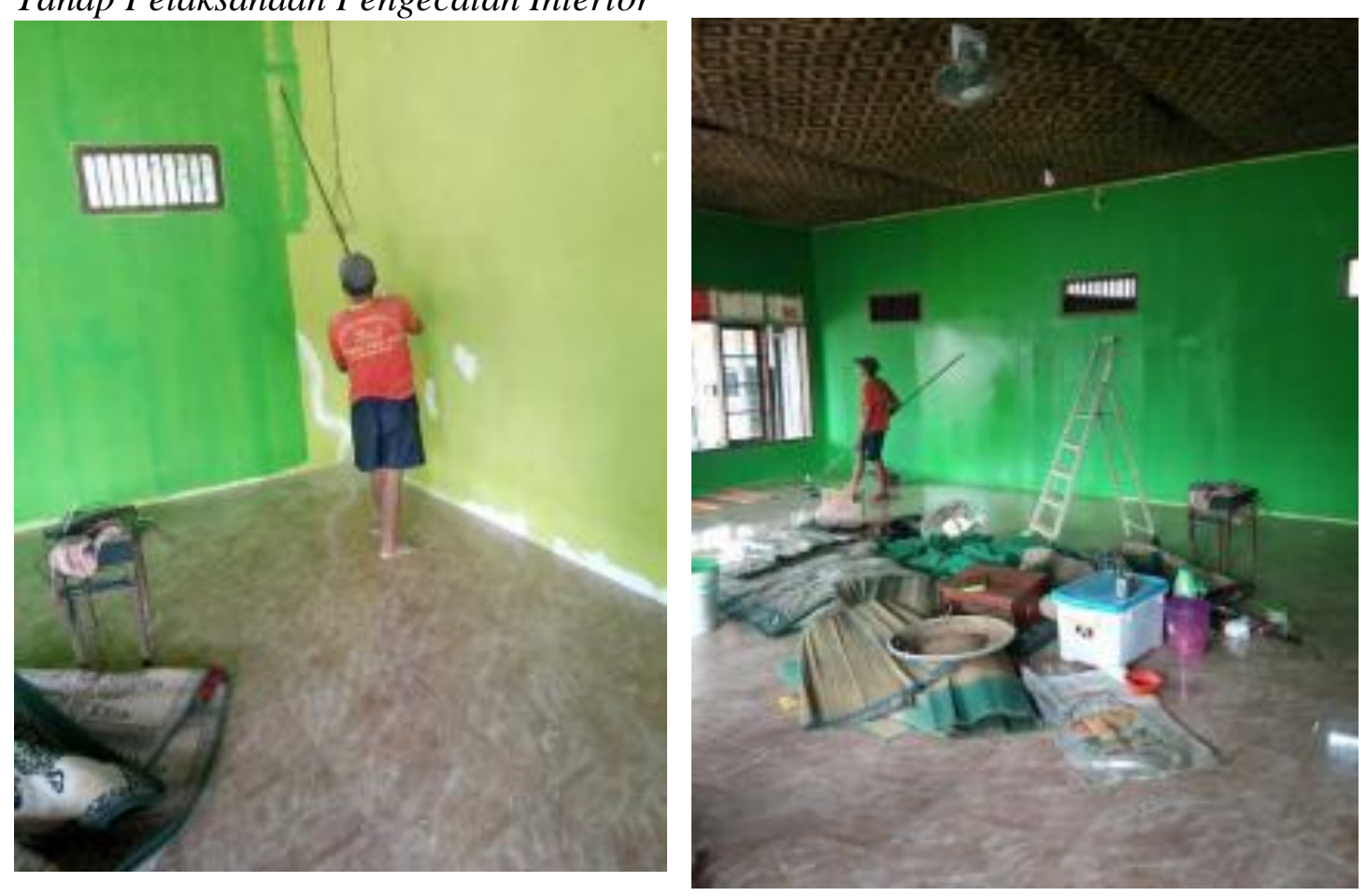

Penataan furniture pada Majelis Taklim meliputi; rak buku, lemari, meja lipat dan white board.

\section{Gambar 4}

Penataan Furniture pada Interior Majelis Taklim

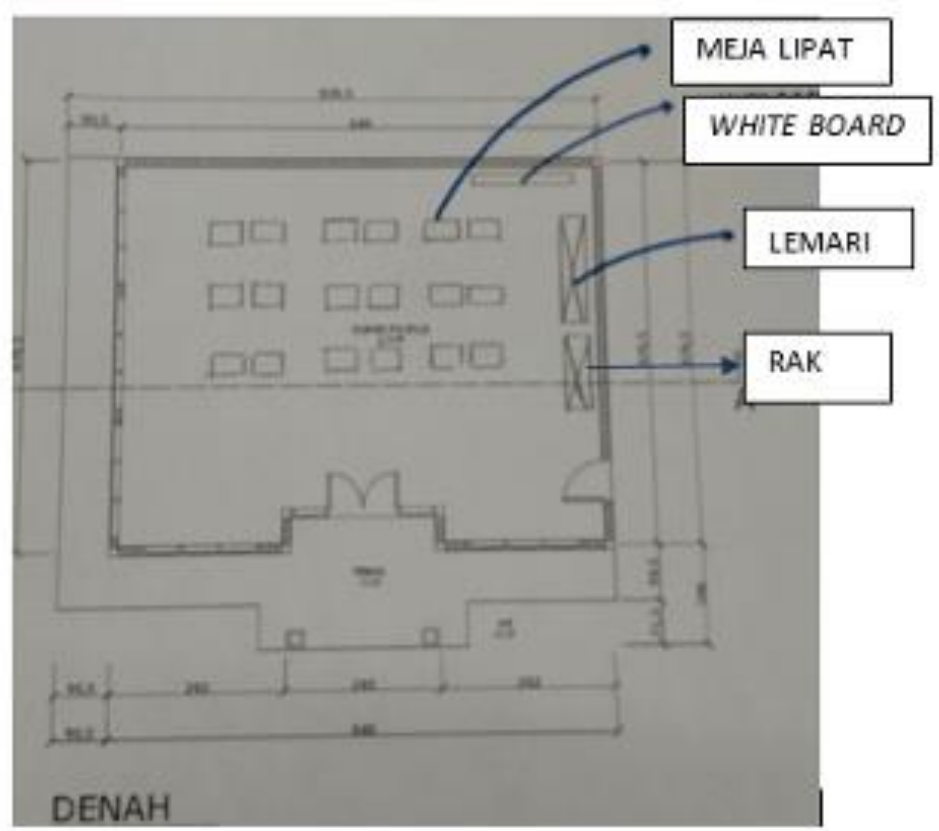


Penataan furniture pada Majelis Taklim Al Musa'adah antara lain:

- White Board

Penambahan papan tulis dipakai untuk kegiatan belajar mengajar keagamaan, sebagai media tulis, supaya memudahkan guru untuk mengajar. White board yang digunakan memiliki ketebalan 9 mm, dengan bahan Plywood; Dimensi Board : $120 \mathrm{~cm}$ X $90 \mathrm{~cm}$; Lapisan : Lembaran Plat Formica Besi Putih Import, yang dilengkapi dengan List Alumunium, serta pada bagian sudut berupa Plastik Rounded warna abu-abu, dilengkapi juga dengan tempat spidol dan pengait di belakang papan .

\section{Gambar 5}

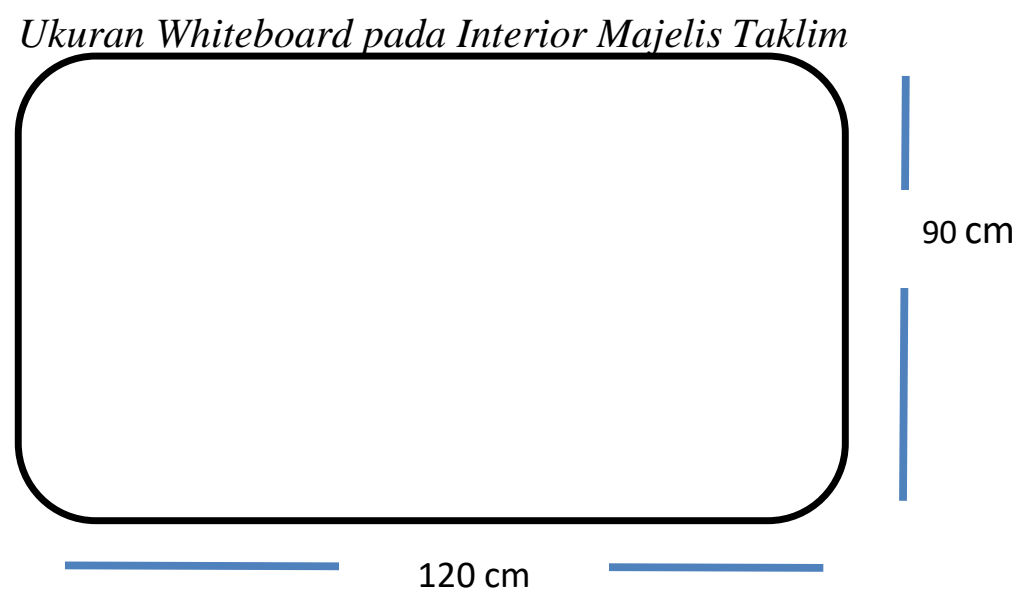

\section{Gambar 6}

Pemasangan Whiteboard pada Interior Majelis Taklim

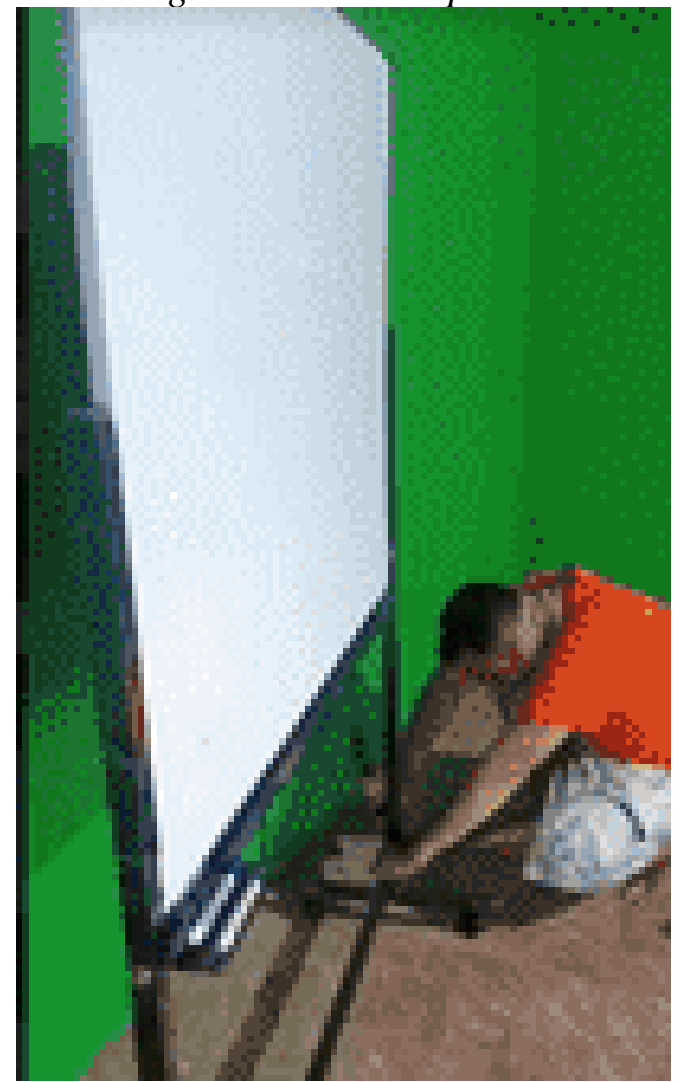


- Meja Lipat

Meja lipat digunakan untuk tempat menulis santri saat kegiatan keagamaan , maupun digunakan sebagai tempat menaruh Al Qur'an serta Iqra saat kegiatan mengaji. Spesifikasi meja lipat antara lain ; dimensi panjang $54 \mathrm{~cm}$, lebar $34 \mathrm{~cm}$, tinggi $22 \mathrm{~cm}$; bahan dasar multiplex 8mm; bahan pelapis pvc supercon (anti air); kaki terbuat dari alumunium dengan alas karet.

- Lemari penyimpanan

Lemari penyimpanan berfungsi sebagai tempat menaruh alat-alat solat, buku keagamaan supaya lebih rapi dan bebas dari debu. Spesifikasi rak penyimpanan antara lain memiliki ukuran: 80 x 40 x 165 cm; bahan: Bahan : kombinasi Particle Board dan MDF (Medium Density Fibreboard).

Lemari penyimpanan ini terdiri dari 5 rak penyimpanan. Rak penyimpanan memiliki bahan yang sama dengan bahan lemari yaitu Particle Board dan MDF (Medium Density Fibreboard.).

\section{Gambar 7}

\section{Meja Lipat pada Interior Majelis Taklim}

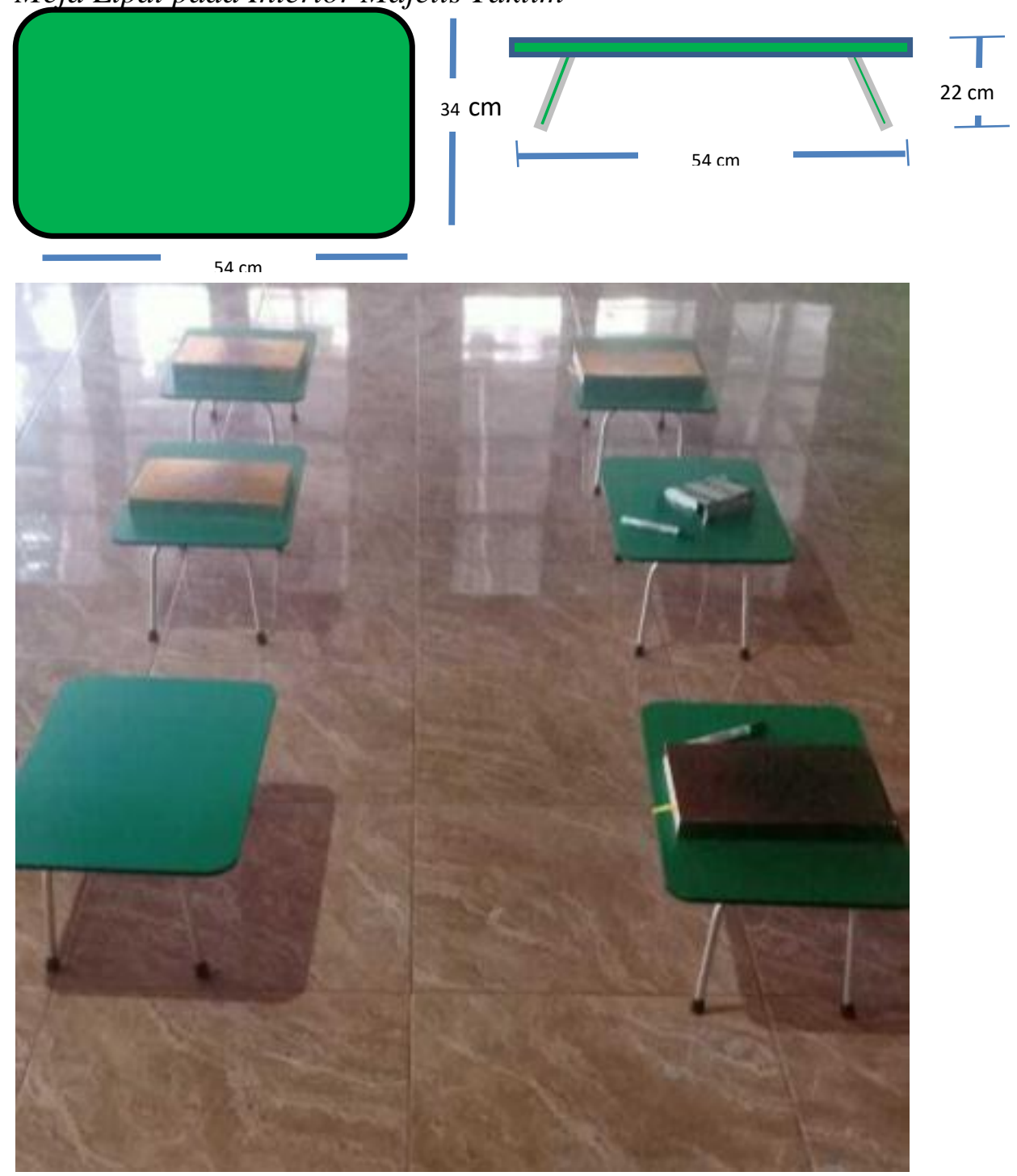




\section{Gambar 8}

Lemari Penyimpanan pada Interior Majelis Taklim
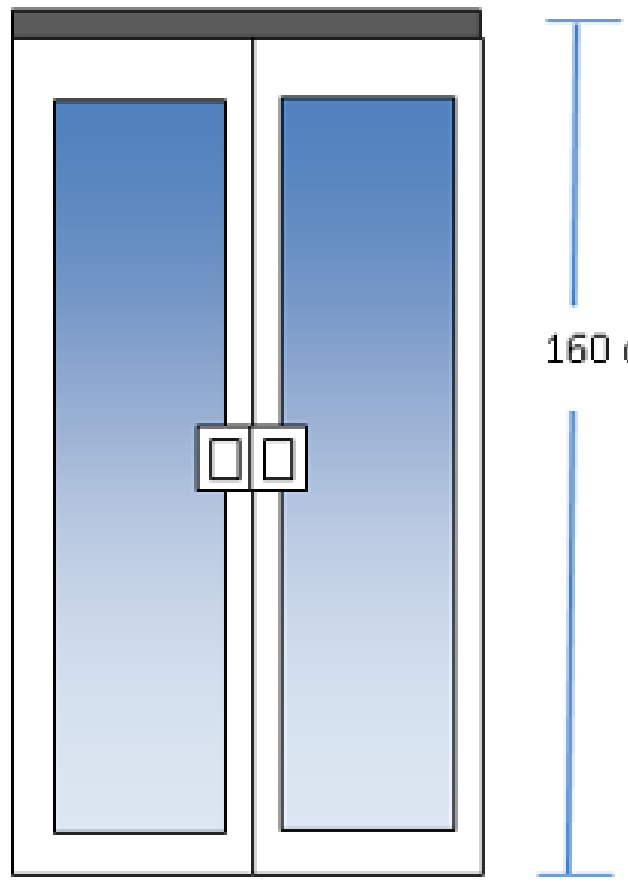

$160 \mathrm{~cm}$

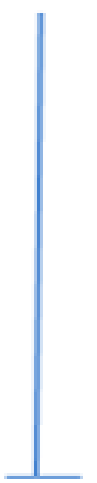

$80 \mathrm{~cm}$

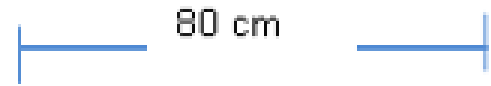

\section{Gambar 9}

\section{Lemari pada Interior Majelis Taklim}
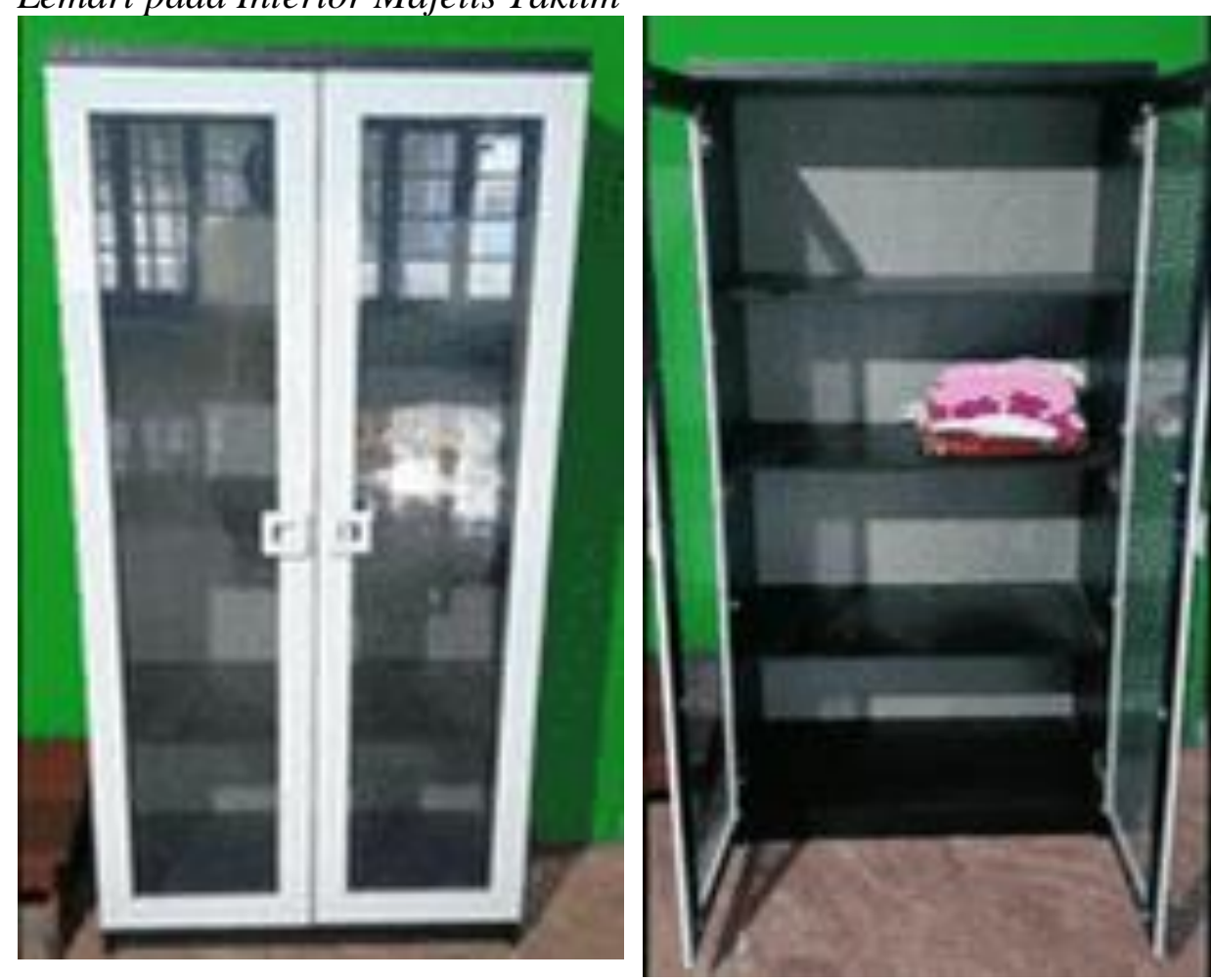


\section{Gambar 10}

Perletakkan Lemari pada Interior Majelis Taklim

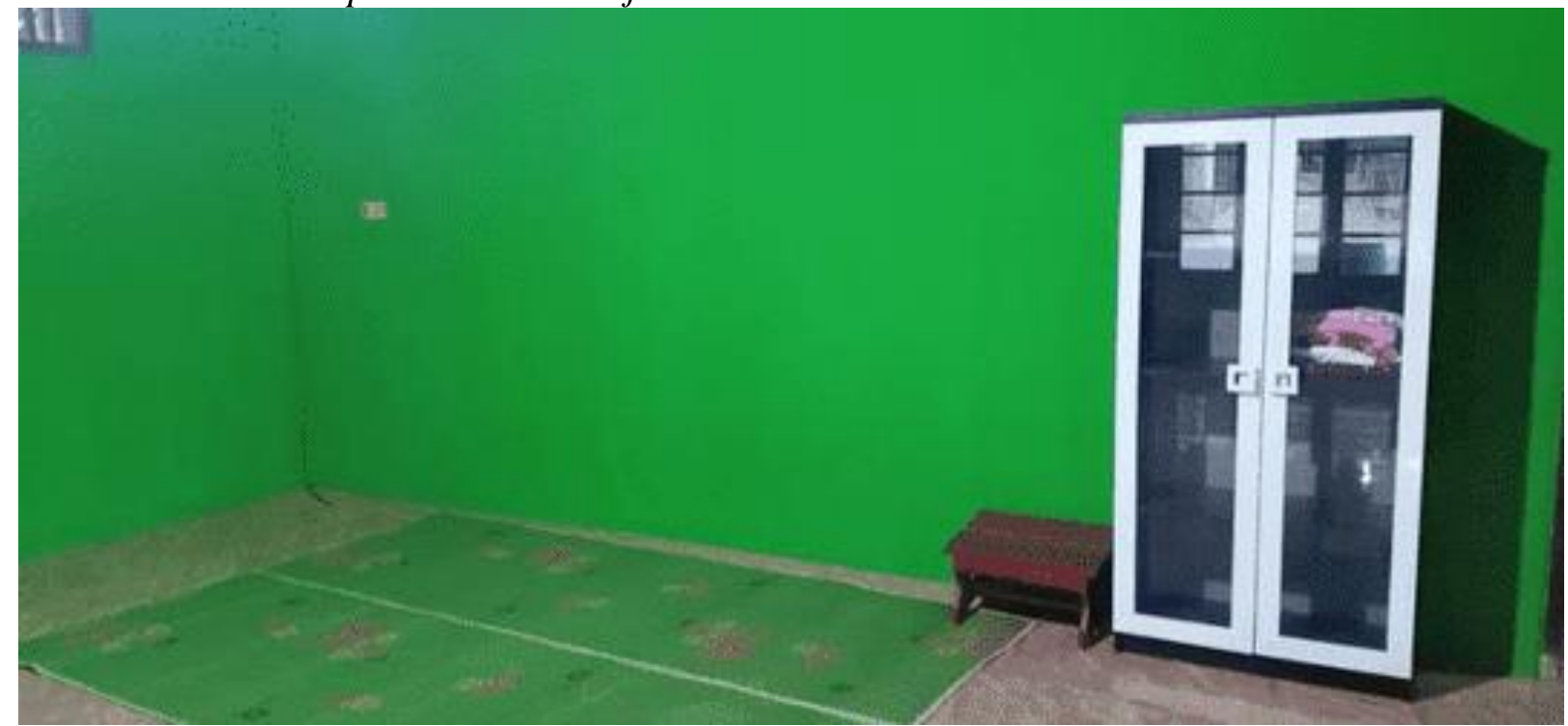

\section{Gambar 11}

Perletakkan White Board dan Meja Lipat pada Interior Majelis Taklim

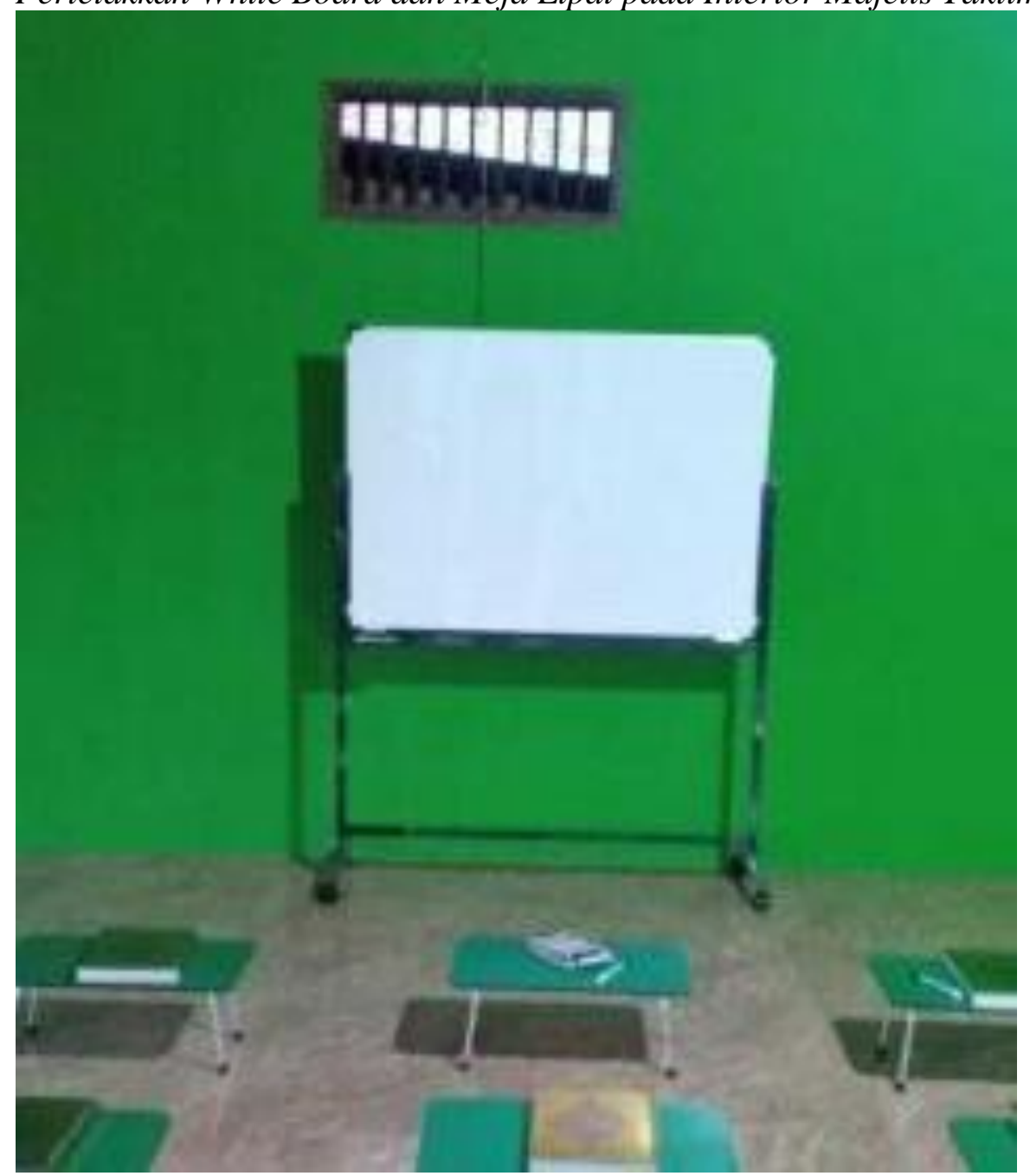




\section{KESIMPULAN DAN SARAN}

Penataan interior pada Majelis Taklim Al Musa'adah berupa perbaikan warna dinding, dengan menerapkan warna yang sering digunakan pada konsep arsitektur islam, yaitu warna hijau sebagai unsur alam, serta penataan furniture antara lain; penambahan meja untuk tempat kegiatan keagamaan serta penambahan rak untuk tempat penyimpanan buku agama serta penambahan white board untuk menunjang kegiatan keagamaan.

Diperlukan peran serta masyarakat sekitar Majelis Taklim untuk menjaga kebersihan, serta merawat sarana dan prasarana yang telah tim lakukan pada perbaikan interior Majelis Taklim. Diharapkan pkm selanjutnya pada bagian elemen interior lainnya seperti; penataan lighting, penambahan kipas angin dan penambahan ornamen pada interior.

\section{REFERENSI}

Binmas Islam. (1995). Pengelolaan Majelis Ta'lim Jakarta.

Mustofa, M. A. (2016). Majelis Ta'lim sebagai alternatif pusat pendidikan islam (Studi Kasus pada Majelis Ta'lim Se Kecamatan Natar Lampung Selatan). Jurnal Kajian Keislaman dan Kemasyarakatan, 1(1).

Helmawati. (2013). Pendidikan nasional dan optimalisasi majelis ta'lim: Peran aktif majelis ta'lim meningkatkan mutu pendidikan. Rineka Cipta.

Irawan, R. F., Sumaryoto, Muqoffa, M. (2019). Penerapan arsitektur islam pada perancangan islamic center Kabupaten Brebes. Jurnal Senthong, 2(1).

Muhsin. (2009). Manajemen majelis ta 'lim: Petunjuk praktis pengelolaan dan pembentukannya. Pustaka Intermasa.

Puslitbang Kehidupan Keagamaan. (2007). Peningkatan peran serta masyarakat dalam pendalaman ajaran agama melalui majelis taklim. Puslitbang Kehidupan Keagamaan.

Undang-Undang Republik Indonesia Tahun 2006 tentang Kewarganegaraan Pasal 26 Ayat 1 (2006). Indonesia. 